Supporting Information

\title{
Thermoresponsive Formation of Dimethyl Cyclodextrin Polypseudorotaxanes and Subsequent One-pot Synthesis of Polyrotaxanes
}

Taishi Higashi, ${ }^{\dagger}$ Jun Li, ${ }^{\ddagger},{ }^{*}$ Xia Song, ${ }^{\star}$ Jingling Zhu, ${ }^{\ddagger}$ Masatoshi Taniyoshi, ${ }^{\dagger}$ Fumitoshi Hirayama, $"$ Daisuke Iohara, " Keiichi Motoyama, ${ }^{\dagger}$ and Hidetoshi Arima ${ }^{\dagger, \#, *}$

${ }^{\dagger}$ Graduate School of Pharmaceutical Sciences, Kumamoto University, 5-1 Oe-honmachi, Chuo-ku, Kumamoto 862-0973, Japan.

${ }^{\star}$ Department of Biomedical Engineering, Faculty of Engineering, National University of Singapore, 7 Engineering Drive 1, Singapore 117574, Singapore.

${ }^{\S}$ Institute of Materials Research and Engineering, A*STAR (Agency for Science, Technology and Research), 3 Research Link, Singapore 117602, Singapore.

${ }^{\|}$Faculty of Pharmaceutical Sciences, Sojo University, 4-22-1 Ikeda, Nishi-ku, Kumamoto 860-0082, Japan.

${ }^{\#}$ Program for Leading Graduate Schools "HIGO (Health life science: Interdisciplinary and Glocal Oriented) Program”, Kumamoto University, 5-1 Oe-honmachi, Chuo-ku, Kumamoto 862-0973, Japan. 


\section{MATERIALS AND METHODS}

\section{Materials}

2,6-Di- $O$-methyl- $\alpha$-cyclodextrin $\quad(\mathrm{DM}-\alpha-\mathrm{CyD}), \quad 2,6-$ di- $O$-methyl- $\beta-\mathrm{CyD} \quad(\mathrm{DM}-\beta-\mathrm{CyD}) \quad$ and 2,3,6-tri- $O$-methyl- $\beta$-CyD (TM- $\beta$-CyD) were purchased from Wako Pure Chemical Industries (Osaka, Japan). 2,4,6-Trinitrobenzenesulfonic acid (TNBS) aqueous solution (1 M), polyethylene glycol (PEG), polypropylene glycol (PPG) and Pluronic P123 were purchased from Sigma-Aldrich (St. Louis, MO). PEG bis-amine was donated by Kawaken Fine Chemicals Co. (Tokyo, Japan). PEG or PPG capped with Z-benzyloxycarbonyl L-phenylalanine moieties (PEG-Zphe ${ }_{2}$ or PPG-Zphe ${ }_{2}$ ) was synthesized according to the method previously reported by Higashi et al. ${ }^{1} \quad$ Other chemicals and solvents were of analytical reagent grade.

\section{Preparation of M-CyD polypseudorotaxanes (PpRXs)}

DM- $\alpha$-CyD (200 mg), DM- $\beta$-CyD (200 mg), TM- $\beta$-CyD (200 mg) or RM- $\beta$-CyD (200 mg) was dissolved in $1 \mathrm{~mL}$ of water, and then $15.4 \mathrm{mg}$ of PEG $(\mathrm{MW}=600-35,000)$ or $17.4 \mathrm{mg}$ of PPG $(\mathrm{MW}=1,000-4,000)$ was added. After sonication for $10 \mathrm{~min}$, the solutions were agitated for $2 \mathrm{~h}$ at various temperatures. Precipitates were collected by centrifugation $(8,000 \mathrm{rpm}, 5 \mathrm{~min})$ and dried under reduced pressure.

\section{Powder X-ray diffraction}

Powder X-ray diffraction patterns were measured by a Rigaku Ultima IV X-ray diffractometer (Tokyo, Japan) with a Ni filtered $\mathrm{CuK} \alpha$ radiation, a voltage of $40 \mathrm{kV}$, a current of $40 \mathrm{~mA}$, a scanning speed of $5 \% \mathrm{~min}$, a time constant of $2 \mathrm{~s}$, and a scan range of $2 \theta=5-35^{\circ}$.

\section{${ }^{1}$ H-NMR}

${ }^{1} \mathrm{H}-\mathrm{NMR}$ spectrum was taken at $25^{\circ} \mathrm{C}$ on a JEOL $\alpha-500$ FT-NMR (Tokyo, Japan) operating at $500 \mathrm{MHz}$, using a $5 \mathrm{~mm}$ sample tube. Deuterated DMSO (DMSO- $d_{6}$ ) was used as a solvent. The stoichiometry of polypseudorotaxanes (PpRXs) or polyrotaxanes (PRXs) was determined by measuring peak areas of the anomeric proton of CyDs and the ethylene protons of PEG or methylene protons of PPG. 


\section{PpRXs formation in the presence of urea}

DM- $\alpha$-CyD (200 mg) or DM- $\beta$-CyD (200 mg) was dissolved in $1 \mathrm{~mL}$ of water containing urea $(0,0.5$ and 1.0 $\mathrm{M})$, and then $15.4 \mathrm{mg}$ of PEG $(\mathrm{MW}=2,000)$ or $17.4 \mathrm{mg}$ of PPG $(\mathrm{MW}=2,000)$ was added. After sonication for $10 \mathrm{~min}$, the solutions were heated at $60^{\circ} \mathrm{C}$ and $50^{\circ} \mathrm{C}$, respectively. Turbidity of the resulting suspensions was measured with a JASCO V-630 UV-visible spectrophotometer (Tokyo, Japan) at $700 \mathrm{~nm}$.

\section{Preparation of DM- $\alpha-C y D$ PRX}

DM- $\alpha$-CyD (2.0 g) was dissolved in $5 \mathrm{~mL}$ of water, and then $77 \mathrm{mg}$ of PEG bis-amine $(\mathrm{MW}=2,000)$ was added. After sonication for $10 \mathrm{~min}$, the solution was heated for $2 \mathrm{~h}$ at $70^{\circ} \mathrm{C}$. TNBS aqueous solution $(1 \mathrm{M}$, $193 \mu \mathrm{L})$ and $\mathrm{NaHCO}_{3}(65 \mathrm{mg})$ were added, and resulting suspension was agitated for $12 \mathrm{~h}$ at $50^{\circ} \mathrm{C}$ in dark. After centrifugation $(8,000 \mathrm{rpm}, 5 \mathrm{~min})$, precipitates were washed 8 times with $4 \mathrm{~mL}$ of hot water $\left(70^{\circ} \mathrm{C}\right)$ and was dried under reduced pressure.

\section{Preparation of PPG tetra-amine}

PPG tetra-amine was synthesized according to the method previously reported by Li et al. ${ }^{2}$ PPG (MW = 4,000, $3.2 \mathrm{~g}$ ) and triethylamine (124 mg) were dissolved in $40 \mathrm{~mL}$ of dichloromethane. After agitation for 30 min, carbonyldiimidazole ( $6.5 \mathrm{~g}$ ) was added to the reaction solution. After $24 \mathrm{~h}$ at room temperature, tris(2-aminoethyl)amine (5.9 g) was added and agitated for $24 \mathrm{~h}$ at room temperature. After evaporation, the sample was washed 3 times with $80 \mathrm{~mL}$ of water and was dried under reduced pressure.

\section{Preparation of DM- $\beta$-CyD PRX}

DM- $\beta$-CyD $(666 \mathrm{mg})$ was dissolved in $2 \mathrm{~mL}$ of water, and then $57 \mathrm{mg}$ of PPG tetra-amine $(\mathrm{MW}=4,000)$ was added. After sonication for $10 \mathrm{~min}$, the solution was heated for $2 \mathrm{~h}$ at $50^{\circ} \mathrm{C}$. TNBS aqueous solution $(1 \mathrm{M}$, $150 \mu \mathrm{L})$ and $\mathrm{NaHCO}_{3}(74 \mathrm{mg})$ were added, and resulting suspension was agitated for $3 \mathrm{~h}$ at $50^{\circ} \mathrm{C}$ in dark. Water $(50 \mathrm{~mL})$ was added and resulting solution was dialyzed against water $(\mathrm{MWCO}=8,000)$, and then the 
sample was lyophilized.

\section{References}

(1) Higashi, T.; Hirayama, F.; Yamashita, S.; Misumi, S.; Arima, H.; Uekama, K. Int. J. Pharm. 2009, 374, 26.

(2) Li, J.; Yang, C.; Li, H.; Wang, X.; Goh, S. H.; Ding, J. L.; Wang, D. Y.; Leong, K. W. Adv. Mater. 2006, 18, 2969. 


\section{SUPPORTING DATA}

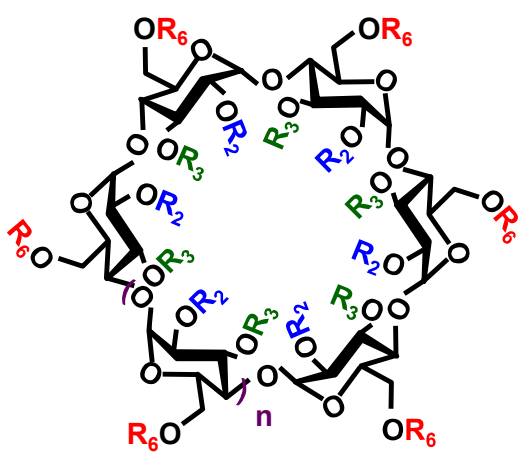

\begin{tabular}{lcccc}
\hline CyD & Abbreviation & Glucose unit & R & D.S. ${ }^{1)}$ \\
\hline 2,6-Di- $O$-methyl- $\alpha$-cyclodextrin & DM- $\alpha$-CyD & 6 & $\mathrm{R}_{2}, \mathrm{R}_{6}=\mathrm{CH}_{3}, \mathrm{R}_{3}=\mathrm{H}$ & 12.0 \\
2,6-Di- $O$-methyl- $\beta$-cyclodextrin & DM- $\beta$-CyD & 7 & $\mathrm{R}_{2}, \mathrm{R}_{6}=\mathrm{CH}_{3}, \mathrm{R}_{3}=\mathrm{H}$ & 14.0 \\
Randomly methylated $\beta$-cyclodextrin & RM- $\beta$-CyD & 7 & $\mathrm{R}_{2}, \mathrm{R}_{3}, \mathrm{R}_{6}=\mathrm{H}$ or $\mathrm{CH}_{3}$ & 12.2 \\
2,3,6-Tri- $O$-methyl- $\beta$-cyclodextrin & TM- $\beta$-CyD & 7 & $\mathrm{R}_{2}, \mathrm{R}_{3}, \mathrm{R}_{6}=\mathrm{CH}_{3}$ & 21.0 \\
\hline
\end{tabular}

Figure S1. Chemical structures of M-CyDs used in this study.

1) The average of substitution of methyl groups. 
Table S1. Yield and Stoichiometry of M-CyD PpRXs with Various Polymers

\begin{tabular}{|c|c|c|c|c|c|c|c|}
\hline CyD & Polymer & $\begin{array}{c}\text { M.W. of } \\
\text { PEG }\end{array}$ & $\begin{array}{c}\text { M.W. of } \\
\text { PPG }\end{array}$ & Yield (\%) & $\begin{array}{c}\text { CyD } \\
\text { number }^{1)}\end{array}$ & $\begin{array}{c}\text { Coverage }^{2)} \\
(\%)\end{array}$ & $\begin{array}{c}\text { Corrected } \\
\text { coverage }^{3)}(\%)\end{array}$ \\
\hline \multirow{7}{*}{ DM- $\alpha-C y D$} & PEG600 & 600 & - & 14.6 & 3.5 & 51.9 & 71.6 \\
\hline & PEG2000 & 2,000 & - & 68.8 & 11.9 & 52.4 & 72.3 \\
\hline & PEG4000 & 4,000 & - & 51.1 & 23.8 & 52.3 & 72.2 \\
\hline & PEG6000 & 6,000 & - & 63.8 & 36.2 & 53.1 & 73.6 \\
\hline & PEG20000 & 20,000 & - & 23.1 & 119.1 & 52.4 & 72.3 \\
\hline & PEG35000 & 35,000 & - & 13.3 & 211.4 & 53.1 & 73.3 \\
\hline & $\begin{array}{l}\text { PEG-PPG-PEG } \\
\text { (Pluronic P123) }\end{array}$ & $880 \times 2$ & 3,990 & 30.9 & 12.4 & 62.0 & 85.5 \\
\hline \multirow{5}{*}{ DM- $\beta-C y D$} & PPG1000 & - & 1,000 & 48.4 & 5.9 & 68.4 & 94.3 \\
\hline & PPG2000 & - & 2,000 & 58.5 & 11.8 & 68.4 & 94.4 \\
\hline & PPG3000 & - & 3,000 & 62.5 & 16.7 & 64.5 & 89.0 \\
\hline & PPG4000 & - & 4,000 & 26.0 & 26.9 & 78.0 & 107.6 \\
\hline & $\begin{array}{l}\text { PEG-PPG-PEG } \\
\text { (Pluronic P123) }\end{array}$ & $880 \times 2$ & 3,990 & 57.2 & 23.3 & 67.7 & 93.4 \\
\hline RM- $\beta-C y D$ & PPG2000 & - & 2,000 & 0 & - & - & - \\
\hline
\end{tabular}

1) Number of total CyD units in the PpRXs.

2) Coverage $=2(\mathrm{CyD}$ per polymer $) /($ polymer repeat units $)$, assuming 2 polymer repeat units per CyD.

3) Coverage calculated by considering the depth of DM-CyD cavity. 
(A) DM- $\alpha-C y D / p o l y m e r$

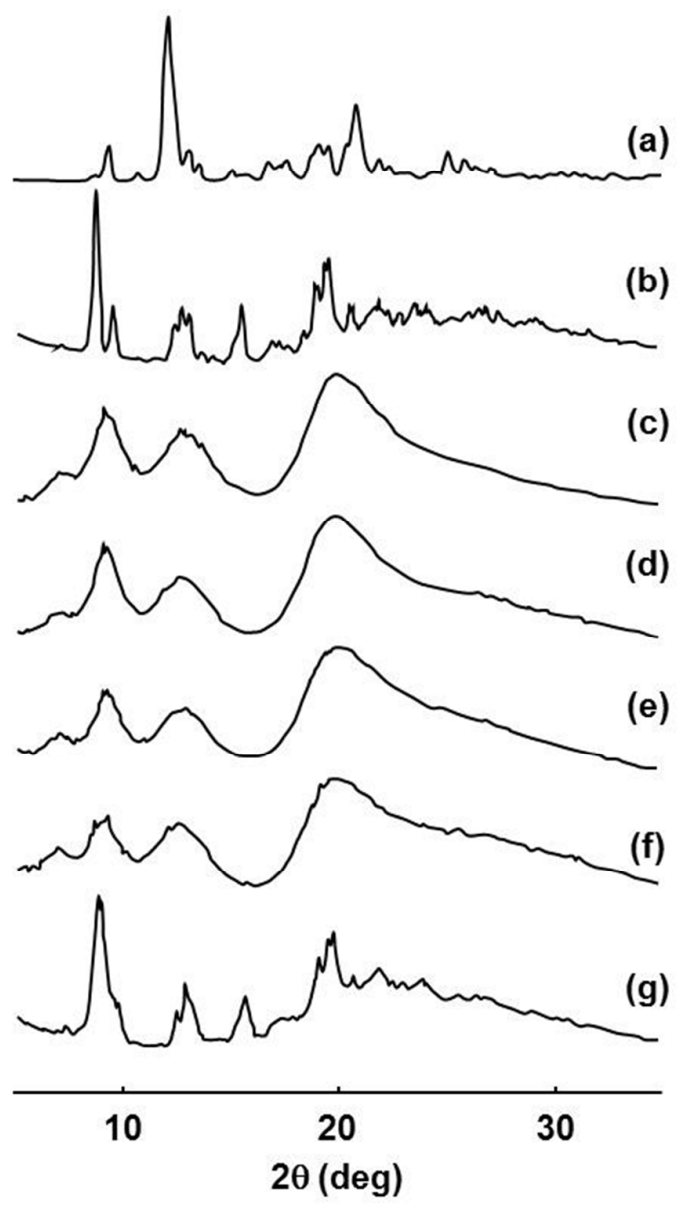

d)
(B) DM- $\beta-C y D / p o l y m e r$
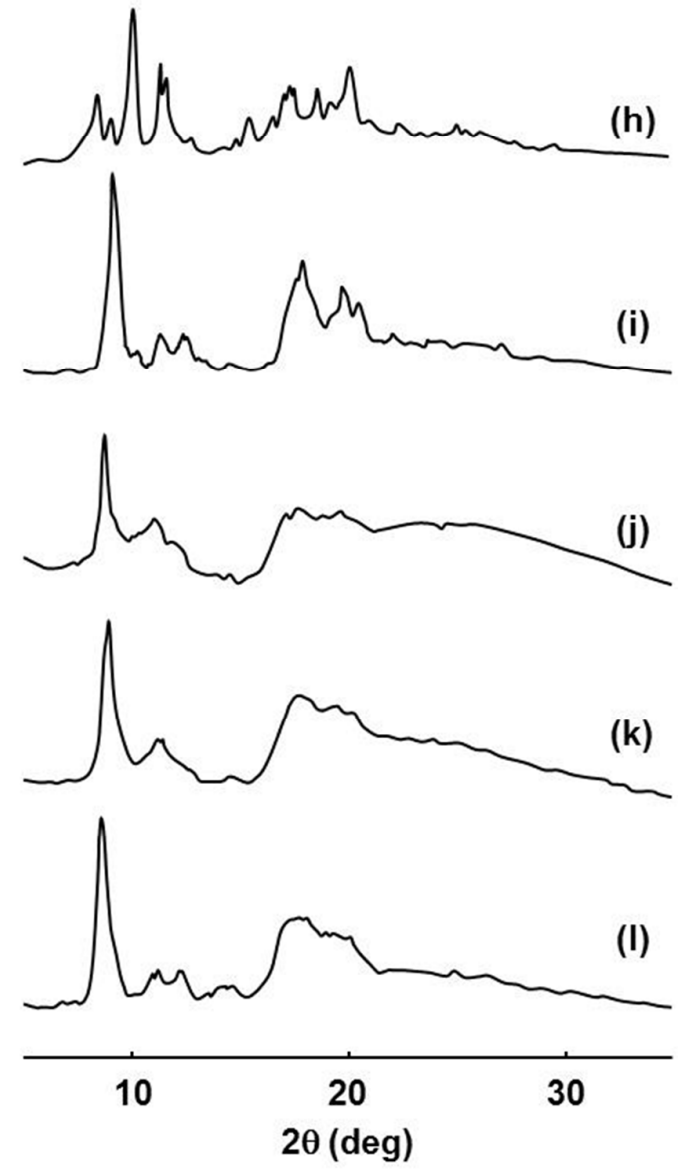

Figure S2. Powder X-ray diffraction patterns of (A) DM- $\alpha-C y D /$ polymers and (B) DM- $\beta$-CyD/polymers PpRXs.

(a) DM- $\alpha-C y D$ alone, (b) DM- $\alpha-C y D / P E G 600 \quad P p R X, \quad$ (c) $\mathrm{DM}-\alpha-\mathrm{CyD} / \mathrm{PEG} 4000 \quad \mathrm{PpRX}, \quad$ (d) DM- $\alpha-C y D / P E G 6000$ PpRX, (e) DM- $\alpha-C y D / P E G 20000$ PpRX, (f) DM- $\alpha-C y D / P E G 35000$ PpRX, (g) DM- $\alpha-C y D / P l u r o n i c \quad P 123 \quad$ PpRX, (h) DM- $\beta$-CyD alone, (i) DM- $\beta-C y D / P P G 1000 \quad$ PpRX, (j)

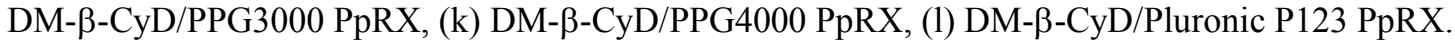


(a) DM- $\alpha-C y D / P E G 600$

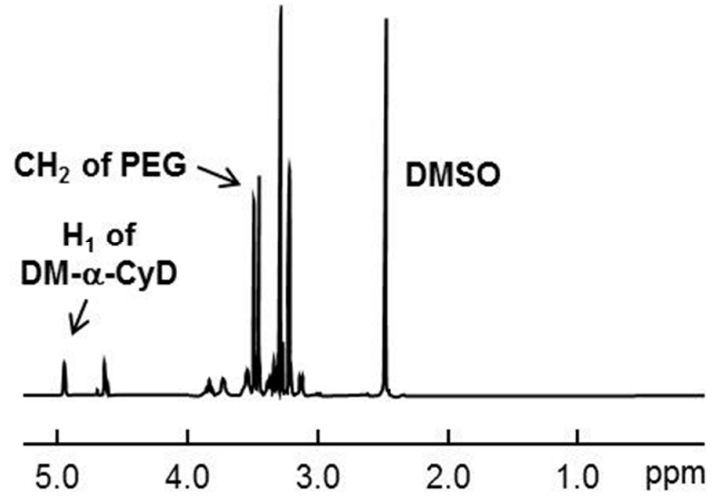

(c) DM- $\alpha-C y D / P E G 6000$

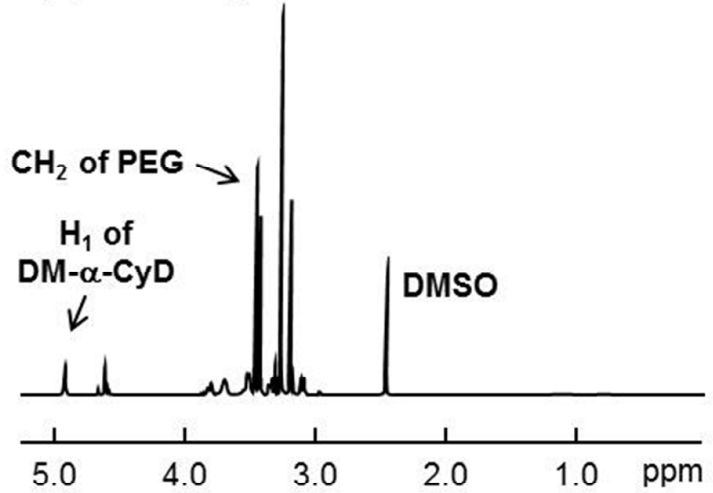

(e) DM- $\alpha$-CyD/PEG35000

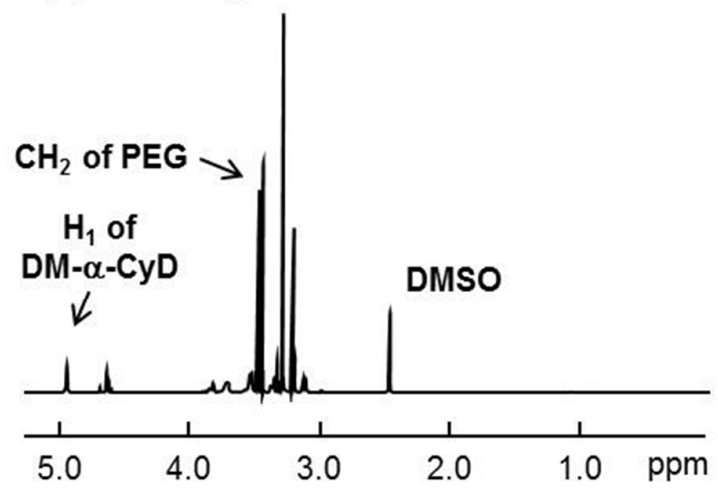

(b) DM- $\alpha$-CyD/PEG4000

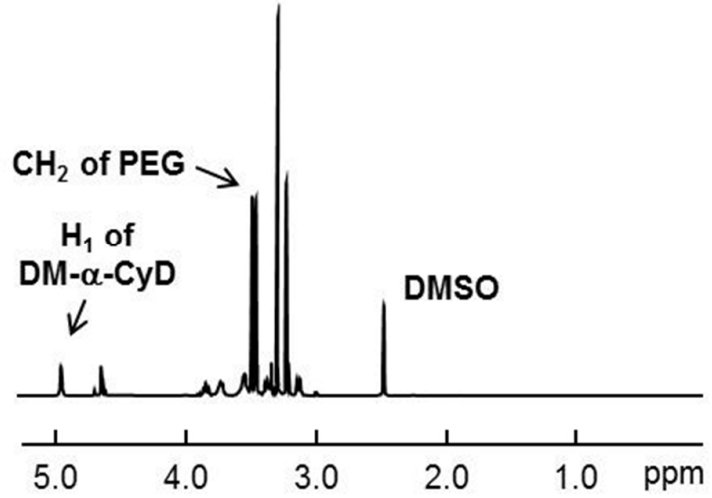

(d) DM- $\alpha-C y D / P E G 20000$

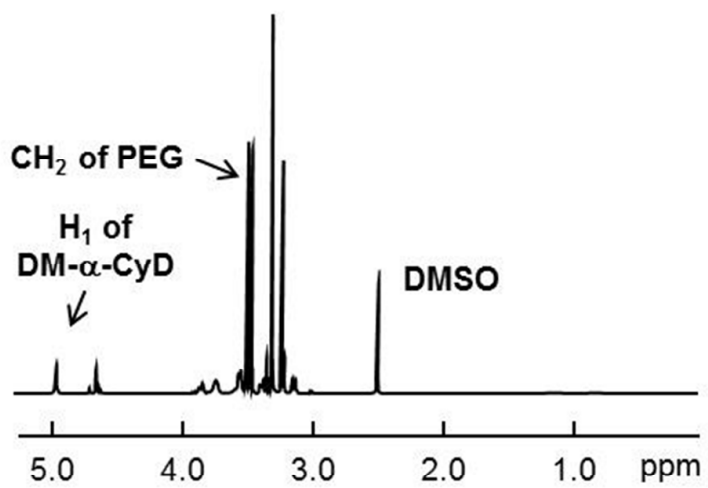

(f) DM- $\alpha-C y D / P l u r o n i c ~ P 123$

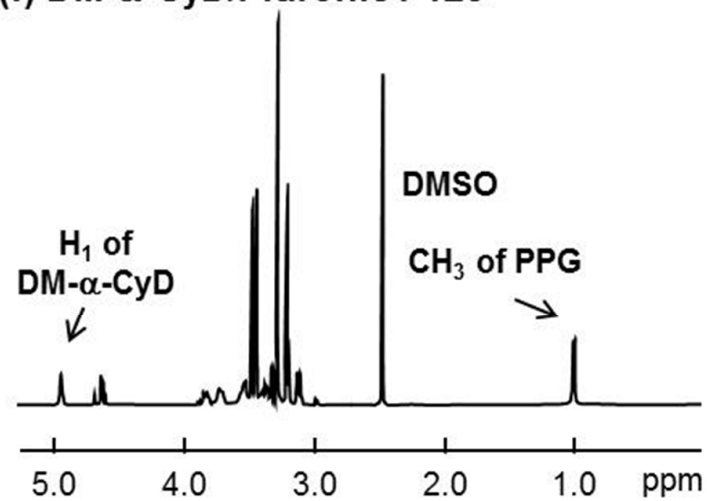

Figure S3. $\quad{ }^{1} \mathrm{H}-\mathrm{NMR}$ spectra of DM- $\alpha-\mathrm{CyD} /$ polymers PpRXs in DMSO- $d_{6}$. 
(a) DM- $\beta$-CyD/PPG1000

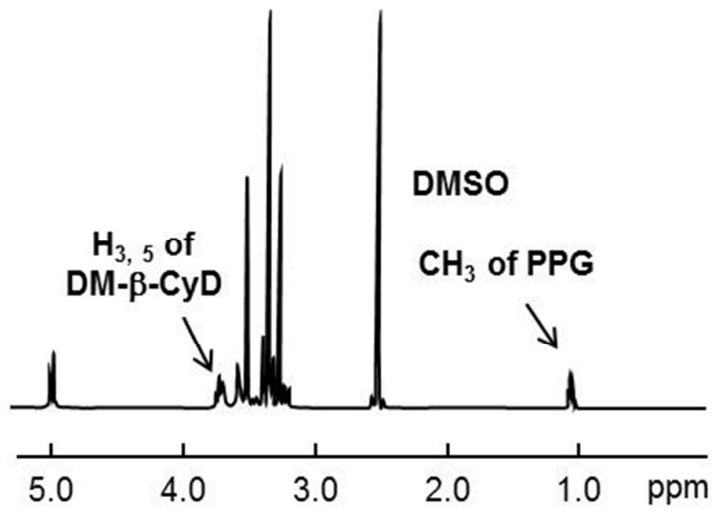

(c) DM- $\beta-C y D / P P G 4000$

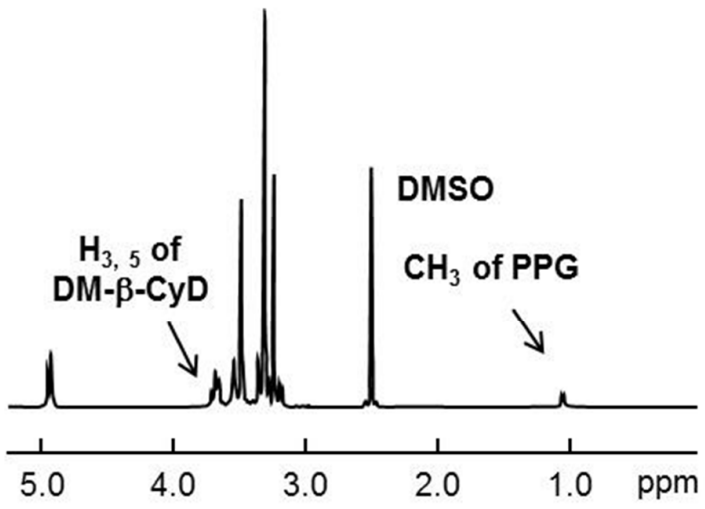

(b) DM- $\beta-C y D / P P G 3000$

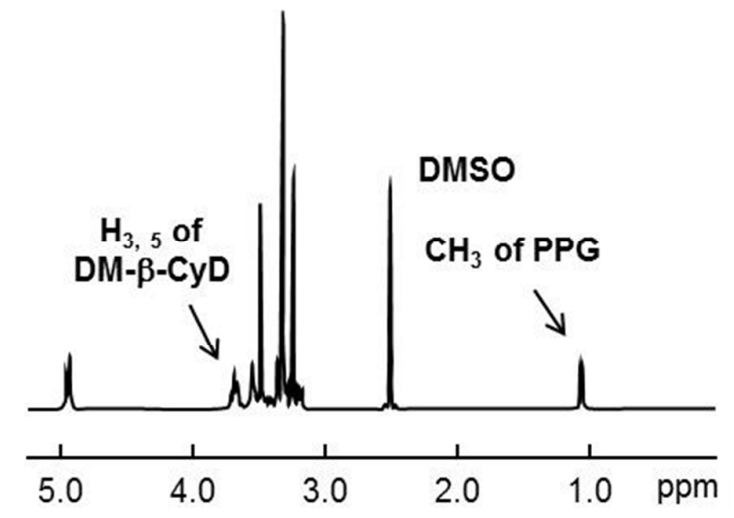

(d) DM- $\beta-C y D / P l u r o n i c ~ P 123$

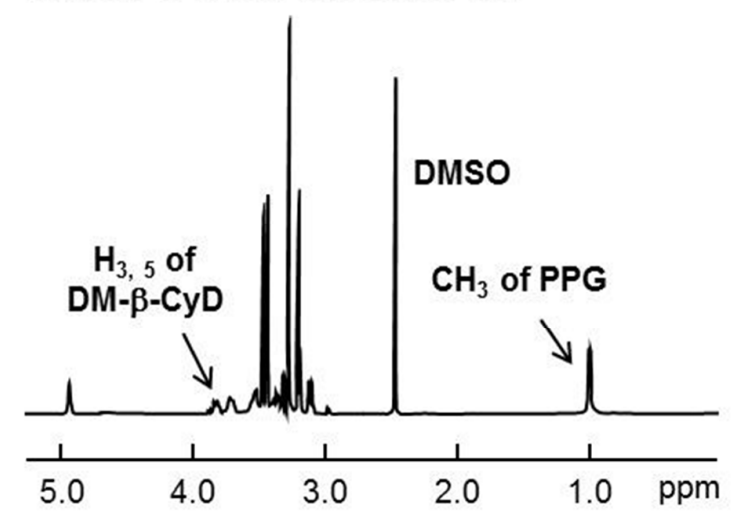

Figure S4. $\quad{ }^{1} \mathrm{H}-\mathrm{NMR}$ spectra of DM- $\beta-\mathrm{CyD} /$ polymers PpRXs in DMSO- $d_{6}$. 
(A) DM-CyD alone
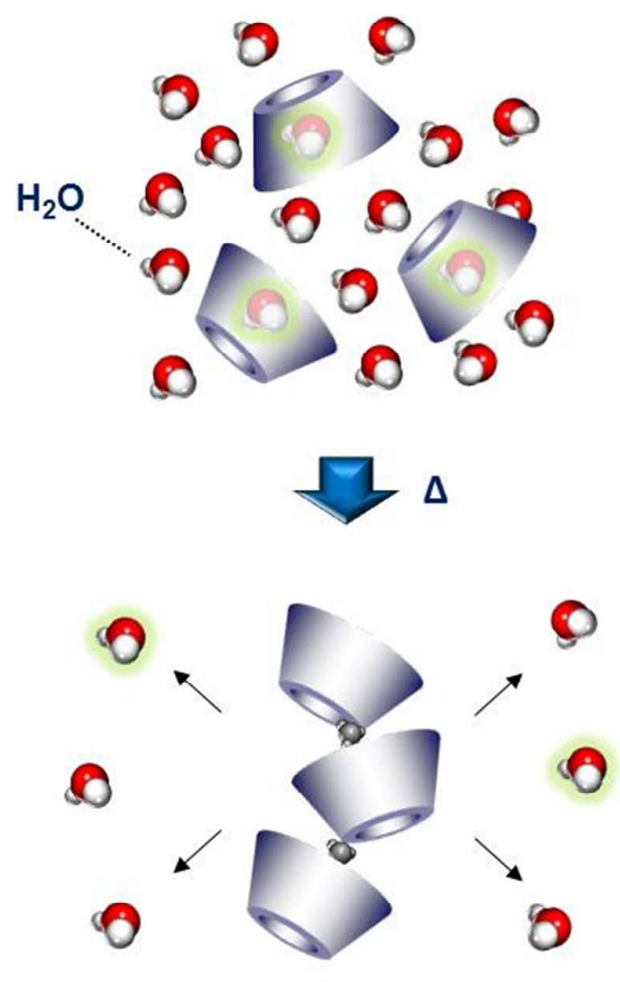

Zigzag type
(B) + Polymer
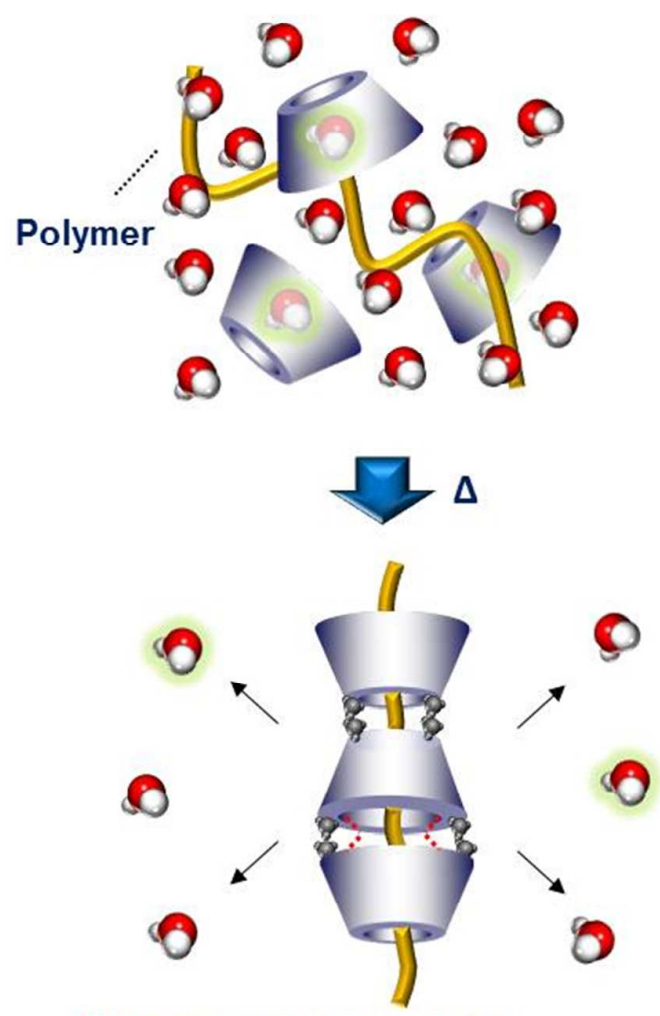

Hydrogen bond of $\mathrm{OH}$

Hydrophobic interaction of $\mathrm{CH}_{3}$

Figure S5. Proposed mechanism for formation of DM-CyD PpRXs 